Luka Culiberg

\title{
Tradicija, modernost in vloga konfucianizma pri izgradnji japonske nacionalne države
}

Ključne besede: konfucianizem, kogaku, kokugaku, rangaku, narod, tradicija, modernost

DOI: $10.4312 /$ ars.10.1.98-116

\section{Uvod}

Sodobne družbe, organizirane v nacionalne države, vsakdanja spontana zavest s svojim akademskim zaledjem v naivnih »kulturnih študijih « ponavadi utemeljuje z ezoteričnim pojmovnim aparatom, katerega paradni konji so kultura, tradicija, modernost, razvoj, nacionalni značaj in sorodni pojmi, s katerimi se družbena divja misel kakor tudi navidezni teoretski družboslovni modeli izognejo potrebi, da bi se dejansko spopadli s težko nalogo teoretske prakse, ki bi poskušala izdelati teorijo družbene strukture. Namesto teoretskega konceptualnega aparata spontana ideologija družbeno organiziranost pojasnjuje s pojmovnim aparatom, ki je že na voljo in ki se je porodil prav iz te družbene strukture.

Za take pojasnitve je značilno, da vedno uspešno "pojasnijo«, kar želijo pojasniti. Te »pojasnitve« so uspešne, ker so tavtološke, pri čemer se njihova tavtološkost skrije v ideološko slepo pego. Tavtologija takih »pojasnitev«, kot je »vaša hči je bolna, ker je zbolela« (Plehanov, 1955, 72), je uspešna formula družboslovne divje misli. Določeno »kulturo« pojasnimo s specifičnimi značilnostmi skupine, za katero predpostavimo, da poseduje to kulturo: japonska kultura je način življenja Japoncev (in ne, na primer, Korejcev). Tavtologija razlage je v tem, da se krožno pojasnjuje: če hočemo pojasniti ta način življenja Japoncev, si pomagamo z japonsko kulturo.

Kadar moramo opredeliti, kaj naj bi sodilo v to kulturo, ponavadi posežemo po konceptu tradicije. Japonska kultura oblikuje japonski nacionalni značaj, elementi te kulture pa so lahko po potrebi bushidō, zenovski budizem, šintoizem ali konfucianizem, če naštejemo le nekaj najbolj klasičnih topoi duhovnega ozadja, ki naj bi navdihovali japonsko »kulturo«. 
Tovrstne kulturne pojasnitve imajo več težav. Na primer, pojasnjevanje določenih vidikov japonske kulture s konfucijansko tradicijo ima to težavo, da obstajajo številne druge družbe s konfucijansko preteklostjo, ki se precej razlikujejo od japonske družbe (Kanazawa, Miller, 2000, 7). Domneve o kulturnih značilnostih, ki jih pojasnjujejo s konfucijanskim učenjem, na primer domnevno japonsko težnjo po politični stabilnosti in spoštovanje vzpostavljenih pravil in avtoritete, hkrati prezrejo, da večji del japonske zgodovine prav nasprotno zaznamujejo številni regionalni vojaški konflikti in kmečki upori (Kanazawa, Miller, 2000, 7). Ker v tem smislu konfucianizem in budizem, ki zaznamujeta številne družbe, nista dovolj, da bi pojasnila »unikatno kulturo«, je treba dodatno poseči po vzporednih »tradicijah«, ki oblikujejo »nacionalni značaj«, na primer, po bojevniškem duhu ali šintoistični tradiciji.

Kulturološke razlage pa pri tem prezrejo še eno pomembno značilnost tako imenovanih »tradicij«; te razlage namreč predpostavljajo, da so bile "predmoderne« družbe statične, da so bile tradicionalne kulture konsistentni sklopi norm in vrednot in da so imele »tradicionalne« družbe homogeno družbeno strukturo (Gusfield, 1967). Vendar stare »kulture« niso bile nič bolj homogene, statične in nekonfliktne. Tudi v njih so se križali različni interesi, tudi v njih so potekali nenehni boji in tudi one so se ves čas spreminjale, še posebej v stiku $\mathrm{z}$ drugimi »kulturami«.

Tisto, kar si danes predstavljamo pod, na primer, »budistično tradicijo«, je namreč produkt modernega budizma (Lopez, 2002), tj. skupka predstav, ki so se izoblikovale v zadnjih 150 letih kot odgovor na evropsko kolonizacijo Azije. Ob stiku "Zahoda" in »Vzhoda " so se budistične tradicije preoblikovale, ${ }^{1}$ tako da bi ustrezale modelu univerzalne religije, in so se kot filozofski sistem približale evropskim znanstvenim in racionalističnim paradigmam (Lopez, 2002, xiii). Moderni budizem in moderni konfucianizem nista nekakšna »izvorna« nauka, ki bi skozi stoletja oblikovala nacionalni značaj družb, ki so bile pred tem statične in nezgodovinske, temveč sta dinamični »izmišljeni tradiciji«, ki sta $\mathrm{v}$ na novo nastajajočih narodih zapolnili strukturna mesta kulture, tradicije in ostalih mehanizmov v procesu vzpostavitve in perpetuiranja nacionalnih družbenih struktur.

1 Sledenje preoblikovanju azijskih tradicij ob stiku $\mathrm{z}$ »Zahodom « nas obenem ne sme napeljati na misel, da je »Vzhod " preprosto prevzel institucije "Zahoda « in se v celoti preoblikoval po zahodni podobi. Ker so bila srečanja od 19. stoletja naprej izrazito neenakovredna srečanja tehnološko in vojaško dominantnega "Zahoda" s šibkejšim »Vzhodom», se je s tega položaja moči razvila specifična vrsta pojasnjevanja narave teh družb, ki jo je Edward Said koncipiral kot orientalizem (Said, 1996), to je način pojasnjevanja, ki predpostavlja ontološko distinkcijo med »Vzhodom « in "Zahodom «, ne ozirajoč se na razmerja moči. Taka vednost, ki nikakor ni bila nevtralna, je za nazaj teleološko »pojasnila« tehnološki primat »Zahoda«, pri čemer je ta primat logično izšel iz kulturne in institucionalne superiornosti »Zahoda «. Trdno vzpostavljena naziranja, ki »Zahodu « pripisujejo iznajdbo takih na videz superiornih atributov, kot so logično mišljenje, racionalizem, nastanek kapitalizma, individualizem itn., izjemno uspešno razbija Jack Goody v svoji razpravi Vzhod na Zahodu (Goody, 2013). 


\section{Paradoks »modernosti«}

Od sredine 19. stoletja so $\mathrm{v}$ večini azijskih dežel potekale hitre družbene spremembe, ki jih klasična družboslovna misel pojasnjuje kot »modernizacijo«. Modernizacija je poleg tehnoloških inovacij in razgradnje določenih družbenih institucij pomenila preoblikovanje družbenih struktur v skupnosti, ki so same sebe začele dojemati kot nacionalne skupnosti. Proces nastajanja novih narodov po vsem svetu, kjer so zahodne imperialistične sile pustile svoj pečat, je namreč pomenil proces preoblikovanja družb v skladu s posebnimi strukturnimi zahtevami, ki so izhajale iz kapitalistične ekonomske formacije.

»Kapitalistično svetovno gospodarstvo« je družbeni sistem, ki je dosegel svojo najizrazitejšo obliko v Evropi v »dolgem« 16. stoletju in ki se je prostorsko širil, dokler ni s pomočjo svojih ključnih političnih enot - nacionalnih držav - zaobjel vseh geografskih področij planeta (Arrighi in dr., 2012, 22). Ko so bila nova območja vključena $\mathrm{v}$ to kapitalistično svetovno gospodarstvo, so bile obstoječe politične strukture teh območij običajno temeljito preoblikovane, često tudi v smislu njihovih teritorialnih in "etničnih « meja, da bi lahko odigrale svoje pričakovane vloge v novi mreži odnosov, ki so jo zaznamovala meddržavna razmerja (Arrighi in dr., 2012, 22). Različne države so na to novo svetovno igrišče vstopale pod različnimi pogoji in $\mathrm{v}$ različni kondiciji. Indija ni bila v enakem položaju kot Kitajska in Kitajska se je soočala z drugačno usodo kakor Japonska (Arrighi in dr., 2012, 22-23).

Spremembe so torej preoblikovale obstoječe družbene strukture, izidi teh procesov pa so se razlikovali glede na zunanje odnose in glede na notranje razmere v posamezni družbi. V vsakem primeru pa so jih določali odnosi moči, se pravi: družbene strukture družb na periferiji svetovnega sistema so se preoblikovale v odnosu do tistih družb v njegovem središču.

Porajajoče se etnične identitete in nastanek nacionalne zavesti v podjarmljenih in koloniziranih družbah so izšli iz protikolonialnih bojev. V Indiji se je poskus otresti se kolonialne nadvlade manifestiral v obliki nacionalističnega boja, medtem ko so na Kitajskem boji, ki so poskušali zaustaviti in obrniti ponižanje in razkosanje s strani tujih sil, dobili obliko republikanskih in komunističnih gibanj (Seth, 2013, 273). Pri tem moramo biti pozorni na to, kakor opozarja Seth $(2013,273)$, da so bila ta gibanja tesno zvezana $\mathrm{z}$ bojem, da bi postali »moderni«:

Dejansko sta se zdela oba cilja ponavadi tako tesno povezana, da ju ni bilo mogoče razločiti: ljudje so morali začeti postajati moderni, če naj bi se kadarkoli osvobodili tuje nadvlade, in morali so si priboriti suverenost in državno moč, da bi se lahko lotili težavne, vendar nujne naloge izgradnje 
močnega, uspešnega in modernega naroda. Zato so si tako v Indiji kakor na Kitajskem politična gibanja konec 19. stoletja hkrati prizadevala vzpostaviti suveren narod, osvobojen nadvlade zahodnih sil, in ta domnevni narod in njegovo ljudstvo narediti »moderna«, hkrati kot sredstvo za nacionalistične cilje in kot cilj sam po sebi (Seth, 2013, 273).

Japonska se je učila na indijski in kitajski izkušnji. V kaotičnih razmerah zadnjih let tokugavskega režima (1603-1868) je bila usoda Indije in Kitajske gotovo eden ključnih dejavnikov pri izbiri poti hitre industrializacije, potem ko je bil fevdalni režim leta 1868 dokončno poražen.

Vendar se je v tej izbiri »modernosti« skrival temeljni paradoks. Da bi se družbe osvobodile kolonialnega statusa oziroma odvrnile grožnjo kolonizacije, so morale postati »moderne « in doseči nacionalno suverenost. To je, kakor ugotavlja Seth (2013, 273), pomenilo, da je treba privzeti številne lastnosti kolonizatorja, kajti kako drugače ga prisiliti, da gre, in kako drugače bi lahko bil samostojni narod, ki bi stopil na mesto kolonizatorja, zmožen igrati enakopravno vlogo med močnimi silami Zahoda. Hkrati pa ideološka predstava teh bojev nikakor ni mogla biti artikulirana kot cilj, da bi postali enaki zahodnjakom, saj v tem primeru ne bi bilo nikakršnega razloga za nacionalistični projekt.

Paradoks je bil torej inherenten projektu modernizacije azijskih družb v zahtevi postati kakor zahodne družbe, a hkrati ostati radikalno drugačen. Seth $(2013,273)$ navaja Sun Yat-sena, ki je Kitajce pozival, naj spremenijo svoje navade, toda ne tako, da bi postali Angleži, ampak tako, da bi lahko postali bolj avtentični Kitajci. Na podoben način je indijski nacionalist Lajpat Rai indijski nacionalizem razumel ne kot projekt postati Anglež, Nemec, Američan ali Japonec, temveč je vztrajal, da »... hočemo postati Indijci, toda moderni, progresivni Indijci, ki so v koraku s časom« (Seth, 2013, 273).

V ozadju ideologije »modernizacije« so se torej odvijali kompleksni procesi. Postati »moderen « je pomenilo postati podoben Zahodu, ideološka negacija tega procesa pa je bil nacionalizem, se pravi proces diferenciacije od Zahoda. V tem prizadevanju po diferenciaciji v procesu poenotenja se je bilo treba opreti na določene družbene prakse in institucije, ki so bile najočitneje drugačne, tem praksam in institucijam, ki so v tem procesu postale homogenizirane, standardizirane in na videz historično »večne«, pa pravimo kultura in tradicija. Da bi postali moderni Indijci, ni bilo dovolj, da so postali moderni, morali so postati tudi Indijci. Ideološko vprašanje, kako ostati Kitajec ali Japonec, je v resnici prikrivalo proces nastajanja Kitajcev ali Japoncev. Nacionalizmi so svoj program gradili na predpostavki obstoja nacionalne identitete prebivalstva, a kakor piše Seth $(2013,237)$, so bili v resnici projekt, ki je šele ustvarjal nacionalno identiteto. 


\section{Japonska modernost}

Japonska je ubrala svojo pot $\mathrm{v}$ »modernost«. Ko so vročekrvni revolucionarji v zadnjih izdihljajih fevdalnega režima sredi 19. stoletja spoznali, da preprosto vztrajanje pri zaprtih mejah in ksenofobni klici po »izgonu barbarov « ( $j o ̄ i$ 攘夷) niso več dovolj, da bi se lahko ubranili tehnološko naprednejših »barbarov«, so spremenili taktiko. Prav tako zagnano, kakor so se pred tem upirali tujcem, so začeli prevzemati tehnološke inovacije in spreminjati svoje institucije, da bi se tem tujcem kar najbolj približali. Da bi se hkrati lahko od njih tudi kar najbolj oddaljili, pa je bilo treba izoblikovati trdno nacionalno identiteto.

Slogan o »izgonu barbarov« je tako v zgodnjih letih obdobja Meiji (1868-1912) zamenjal projekt ekonomskega bogatenja države in razvoja močne vojske (fukoku $k y o ̄ h e i$ 富国強兵), kar je postal temelj političnega delovanja nove mejdžijevske elite. Ideološka razrešitev protislovja, ki je družbo postavljalo v položaj, ko je morala hkrati postati »moderna«, se pravi "zahodna«, in si zagotoviti svojo »drugačnost«, je bila povzeta $\mathrm{v}$ še enem sloganu druge polovice 19. stoletja, namreč wakon yōsai 和魂洋 才, kar bi lahko prevedli kot »japonski duh, zahodnjaško znanje«. Ne glede na velike materialne in institucionalne spremembe družbe je lahko Japonska ohranila svojo izjemnost na simbolni ravni $\mathrm{z}$ vero $\mathrm{v}$ ohranitev nedoločljivega ideološkega pojma »japonskega duha«. To je ta skrivnostni »duh naroda«, ki v imenu nacionalizmov preganja večino modernih narodov.

Modernizacija Japonske, ki je temeljila na premisi o zahodni tehnologiji in japonskem duhu, je bila torej v svojem bistvu proces zamišljanja nove nacionalne skupnosti in njenih iznajdenih tradicij. Iznajdba tradicije seveda ne pomeni, da si skupnost ex nihilo izmisli določene družbene prakse, običaje, navade, simbole, rituale itn., kakor skušajo s tako radikalno interpretacijo včasih konservativni kritiki izpodbijati veljavnost tega splošno znanega Hobsbawmovega koncepta. "Iznajdba« tradicije ni "kreacija « tradicije, temveč je bricolage - izdelek, sestavljen ad hoc iz obstoječe brkljarije, nekakšen nov izdelek iz obstoječega odpadnega materiala. Vsak element je imel pred tem določeno funkcijo ali vlogo, v novem izdelku pa mu je dodeljena nova vloga. ${ }^{2}$

Steber tokugavske družbe naj bi bila konfucijanska misel, kar pa nikakor ne pomeni, da je konfucijanstvo na Japonskem živelo svoje intelektualno življenje le kot ortodoksna linija te ali one filozofske smeri, pač pa je šlo, nasprotno, za izjemno eklektično idejno ozadje, na katerem so se oblikovale številne interpretativne smeri,

2 Tradicije v tem smislu nekatere stare elemente vpeljejo v nov kontekst (navadno kontekst kapitalistične formacije), ki v obliki družbenih institucij homogenizirajo kulturno polje družb, te pa v svojih reprezentacijah ustvarjajo navidezne kulturne otoke, v okviru katerih vzpostavljajo svoje identitetne mehanizme. Zakaj je v času dominacije transnacionalnega kapitala v ideološkem polju tako močna potreba po kulturnih reprezentacijah, je drugo vprašanje. 
vključno s tistimi, ki so konfucijanstvo v celoti zavračale. V splošnem pa lahko $\mathrm{v}$ tem obdobju prepoznamo vsaj štiri osnovne idejne paradigme: »kitajsko učenje» ali kangaku 漢学, "starodavno učenje« ali kogaku 古学, „domovinsko učenje» ali kokugaku 国学 in »zahodno učenje« ali rangaku 蘭学.

\section{Kangaku 漢学}

Tokugavska družba (1603-1868) sicer nikakor ni bila tako sinificirana kakor na primer kraljestvo Joseon 朝鮮 (1392-1897) na korejskem polotoku in med raziskovalci intelektualne zgodovine obstajajo različna mnenja glede vpliva konfucijanske misli na tokugavsko družbo v celoti. Kljub temu pa bi težko podvomili o vplivu konfucijanstva na preoblikovanje japonskega političnega establišmenta v uradniški aparat in o njegovi vlogi pri ideološki utemeljitvi te specifične politične realnosti. ${ }^{4}$

Ko je znameniti filozof Inoue Tetsujirō (1855-1944) konec 19. stoletja v Parizu evropski publiki predaval o zgodovini japonske filozofije v obdobju Tokugawa, je svoje predavanje začel s Fujiwarom Seikom (1565-1619), prvim mislecem, ki naj bi na Japonsko vpeljal Zhu Xijevo (1130-1200) filozofijo, danes poznano predvsem pod imenom »neokonfucijanstvo «. ${ }^{5}$ Seikov najznamenitejši učenec je bil Hayashi Razan (1583-1657), ki je temeljne Zhu Xijeve koncepte vpeljal na področje šolstva in jih uspešno uveljavil kot načela izobraževanja v vladnih šolah (Carus, 1899, 274).

Ne dolgo po tem, ko je Fujiwara Seika neokonfucijansko misel vpeljal na Japonsko, je novo in drugačno miselno smer ubral Nakae Tōju (1608-1648), ki je bil sledilec Wang Yangminga (1472-1529), mingovskega filozofa, ki je konfucijanstvo poskušal združiti z budizmom. Ta šola je, kakor je menil Inoue, na Japonskem igrala pomembno vlogo, saj je vplivala na izobražene sloje prebivalstva (Carus, 1899, 274-275).

3 Šolo »zahodnega učenja navadno imenujejo s skupnim imenom rangaku 蘭学, pri čemer pismenka ran 蘭 predstavlja Nizozemsko, edini evropski vir informacij v dveh stoletjih tokugavske vladavine.

4 Konfucijanski mislec Kumazawa Banzan (1619-1691), ki si je prizadeval konfucijanstvo vpeljati na Japonsko, je bil v teh prvih letih tokugavskega režima prepričan, da so na Japonsko prišli že prav vsi elementi kitajske kulture razen »resnične morale in Poti Velikega učenja«, tj. konfucijanstva. Kurozumi (1994) meni, da je imel Banzan le delno prav v svojih ocenah glede položaja konfucijanstva v japonski zgodovini: »Do 16. stoletja se je konfucijanstvo kot intelektualna obrt že razširilo med budisti, šintoističnimi teologi, dvornimi učenjaki in med delom kulturne elite. Kot splošni idejni sistem je pustilo sledi v zakonodaji, hišnih pravilih in literarnih delih. Vendar pa se je za razliko od predtokugavskega konfucijanstva, ki ni imelo dovolj lastnega značaja, da bi ga Banzan sploh opazil, tokugavsko konfucijanstvo na splošno tako močno razširilo, kakor si Banzan ni upal niti sanjati. Vendar pa je bila vsebina te ,poti‘ precej drugačna od tiste, ki si jo je zamišljal Banzan « (Ooms, Kurozumi, 1994, 339).

5 Treba je sicer opozoriti, kakor poudarja Kurozumi, da je celotno tokugavsko konfucijansko misel izredno problematično obravnavati preprosto kot »neokonfucijanstvo« ali kot Zhu Xijev nauk. Tudi sam Fujiwara Seika, ki ga poznamo kot ustanovitelja tokugavske konfucijanske šole, je bil zelo strpen in odprt do različnih tradicij »kitajskega učenja« (Ooms, Kurozumi, 1994, 343). 
Tretjo smer je ubral Yamazaki Ansai (1619-1682), ki se je izšolal v budističnem samostanu, nato pa ustanovil novo šolo, ko se je od budizma obrnil h konfucijanstvu. To ga navsezadnje ni zadovoljilo, zato se je Ansai posvetil študiju šintoizma, ki ga je poskušal pojasniti skozi prizmo Zhu Xijeve filozofije (Carus, 1899, 276).

Ti filozofi, skupaj z drugimi pomembnimi misleci 17. in 18. stoletja, kot so Yamaga Sokō (1622-1685), Itō Jinsai (1627-1705), Kaibara Ekken (1630-1714), Ogyū Sorai (1666-1728), Oshio Chūsai (1793-1837) in drugi, so ne glede na medsebojne razlike in ne glede na odstopanja od Zhu Xijeve ortodoksije vsi po vrsti vztrajali, da je Konfucijeva misel vzor filozofije, in tudi kadar se v čem niso strinjali z njegovimi doktrinami, so se imeli le za razlagalce njegovih stališč (Carus, 1899, 280).

$\mathrm{V}$ trenutku padca tokugavskega režima $\mathrm{v}$ poznih 60 . letih 19. stoletja tako naletimo na družbo, katere intelektualni sloj je prežet s konfucijansko miselnostjo, a so hkrati številni misleci predhodnih dveh stoletij zavijali vstran od te smeri in jo kritizirali, pač $\mathrm{v}$ skladu z nenehno spreminjajočo se družbeno realnostjo.

Četudi japonski filozofi večinoma torej niso neposredno napadli veljavnosti konfucijanske etike kot konceptualnega aparata, s katerim lahko analiziramo obstoječo družbo in spoznavamo realnost, je bila konfucijanska doktrina kljub temu podvržena precejšnjim spremembam in reinterpretacijam. Najita $(1975,933)$ v svoji razpravi navaja primer Kaibara Ekkena (1630-1714), ki je proti koncu življenja napisal delo z naslovom Taigiroku 大疑録 (Zapisi velikih dvomov). V delu, ki velja za enega ključnih dokumentov $\mathrm{v}$ zgodovini tokugavske konfucijanske misli, je eksplicitno zavrnil neokonfucijansko metafiziko. $V$ tej razpravi si je Ekken prizadeval za bolj empirični pristop $\mathrm{k}$ proučevanju narave, ki ga ne bodo omejevale spone metafizične etike, zato je poskušal neokonfucijanski racionalno organizirani sistem znanja združiti $\mathrm{z}$ »domačimi« etičnimi prepričanji - način razmišljanja, ki ga je v precejšnji meri delil $\mathrm{z}$ do neokonfucijanstva kritično filozofsko šolo, s tako imenovanim »starodavnim učenjem « (kogaku), katere najznamenitejša predstavnika sta Ogyū Sorai (1666-1728) in njegov učenec Dazai Shundai (1680-1747) (Najita, 1975, 933-934). V tem smislu Ekken neokonfucijanstva ni videl kot vrednostnega sistema, ki bi nadomestil obstoječa etična prepričanja, temveč je neokonfucijansko univerzalno načelo razumel kot skladno $\mathrm{z}$ »japonskim duhom «:

Spoštovanje staršev, zvestoba, resnicoljubnost, spoštovanje do starejših in do naravnega reda stvari so na Japonskem obstajali kot prepričanja že $\mathrm{v}$ tako imenovani »dobi bogov« (jindai), še pred prihodom kitajske kulture. Japonsko lahko zato ustrezno imenujemo »dežela bogov" (shinkoku), v nasprotju s Kitajsko, ki je»dežela modrecev« (seikoku). Vendar všintoističnem spiritualizmu ni bilo ničesar iracionalnega. Starodavne japonske mitologije, 
kakršna je Kojiki, so bile zavajajoče in niso vsebovale resničnega pomena šintoja, ki ga lahko dejansko bolje razumemo z branjem konfucijanskih klasikov in še posebej s študijem neokonfucijanske filozofije (Najita, 1975, 934).

Že ob vpeljavi neokonfucijanske doktrine na začetku obdobja Tokugawa je torej obstajala zavest o konceptualnem razkolu med domačo filozofsko ali spiritualno tradicijo in uvoženo filozofsko šolo. Konfucijanci so se kmalu oddaljili od ortodoksnega učenja Zhu Xija in svoje interpretacije prilagodili družbeni realnosti tokugavske družbe. Nekateri so poskušali neokonfucijansko učenje konceptualno združiti s tistim, za kar so verjeli, da je avtohtona filozofska tradicija, drugi, na primer pripadniki »domovinskega učenja» (kokugaku) ali »zahodnega učenja» (rangaku), pa so kritizirali konfucijanstvo v celoti. Vendar pa je bila tudi njihova kritika trdno ukoreninjena $\mathrm{v}$ konfucijansko razumevanje tega, kaj je »domovinsko učenje« oziroma kaj je »zahodno znanje«.

Vendar pa reinterpretacij neokonfucijanskih doktrin ne smemo razumeti le skozi prizmo stika $\mathrm{z}$ japonskim »domorodnim« filozofskim svetom in s svetom zahodnega znanja. Družbene spremembe, ki so se dogajale v tokugavski družbi in so fevdalno bojevniško družbo počasi preobražale $\mathrm{v}$ uradniško državo $s$ hitro rastočim meščanskim razredom, velikimi trgovskimi središči, denarno ekonomijo z razvitim bančnim sistemom itn., so same na sebi zahtevale nove interpretacije družbene realnosti.

Epistemološki prelom Kaibara Ekkena, ki je proučevanje narave odcepil od neokonfucijanske metafizike in razmišljanja o etiki (Najita, 1975, 939), je pomenil jasen odmik od neokonfucijanske ortodoksije, ki je temu, čemur so pozneje rekli znanost, omogočil samostojen obstoj v okviru konfucijanske paradigme. Ekken je bil le en primer v splošni intelektualni težnji tokugavskega konfucijanstva k zanikanju metafizične etike. Najita $(1975,940)$ celo pravi, da na Japonskem dejansko nikoli ni bilo »ortodoksne« neokonfucijanske filozofije in da je že Hayashi Razan, prvi ravnatelj uradne neokonfucijanske šole na Japonskem, anticipiral Ekkenov »materialistični monizem«.

Kar bi radi tu poudarili, je kompleksen ustroj tokugavske filozofske misli. $\mathrm{V}$ tem obdobju, ko je bilo z vzpostavitvijo konfucijanske akademije Zhu Xijevo neokonfucijanstvo $\mathrm{v}$ določenem smislu sprejeto kot uradna državna doktrina, namreč niso hkrati nastali le miselni tokovi, ki so konfucianizem na tak ali drugačen način zavračali, na primer »starodavno učenje«, »domovinsko učenje« in »zahodno učenje«, temveč so tudi znotraj uradne konfucijanske šole obstajali številni epistemološki odkloni in kritične reinterpretacije. Najita $(1975,941)$ celo meni, da so se Ekkenove ideje $\mathrm{v}$ precejšnji meri prekrivale s koncepti, ki so se izoblikovali v opoziciji do 
neokonfucijanske šole, se pravi z idejami starodavnega učenja kogaku, kakršne sta oblikovala Ogyū Sorai (1666-1728) in njegov učenec Dazai Shundai (1680-1747), ki sta neokonfucijansko metafiziko zavrnila $\mathrm{z}$ argumentom, da zamegljuje razmerje med etiko in naravo.

Nove zgodovinske razmere so zahtevale drugačne poglede na družbeno realnost, vendar to še nikakor ni pomenilo, da so se morale nove idejne sheme med seboj nujno ujemati. Za razliko od Ekkena so se zagovorniki starodavnega učenja bolj kakor $\mathrm{k}$ naravi usmerili k vprašanjem etike. Etiko so razumeli kot del medsebojno povezanega sveta časa, zgodovine, jezika in še posebej politike, medtem ko po drugi strani človeški razum narave ni zmožen v celoti zapopasti. Lahko jo opazuje, a njena temeljna načela mu ostajajo nerazumljiva (Najita, 1975, 941).

Ogyū Sorai je menil, da so etiko in politiko ustvarili ljudje, zato sta ločeni od ideje »narave«. Zato je bila zanj prava znanost zgodovina in ne narava. Kaibara Ekken pa je v skladu $\mathrm{z}$ neokonfucijansko premiso, da ljudje lahko racionalno in objektivno opazujejo stvari, verjel, da naravo v končni instanci lahko razumemo, medtem ko notranjega etičnega doživljanja ljudi verjetno ne moremo (Najita, 1975, 941-942).

Uvid v procese preoblikovanja notranje strukture neokonfucijanske misli kakor tudi zavedanje o idejnem prekrivanju $\mathrm{z}$ načeloma do konfucijanstva kritičnimi tokovi filozofskih šol v tokugavskem obdobju je pomemben za razumevanje oblikovanja "moderne« nacionalno organizirane japonske družbe v naslednjem, mejdžijevskem obdobju (1868-1912). Zmotno bi bilo, če bi preprosto predpostavili, da je bilo Zhu Xijevo neokonfucijanstvo kot uradna ideologija tokugavske družbe homogeno in $\mathrm{v}$ svoji ortodoksni obliki prvič postavljeno pod vprašaj šele s šolo starodavnega učenja, v okviru katere je Ogyū Sorai spodkopal konstitutivne miselne sheme ideologije konfucianizma, ko je postavil ločnico med naravne in moralne zakone. Kakor smo videli, so se podobni prelomi $\mathrm{z}$ ortodoksijo zgodili že znotraj same uradne šole neokonfucijanstva, ki je že od samega prihoda v japonski politični in idejni prostor začela svojo pot $\mathrm{v}$ heterodoksni maniri različnih interpretacij. Starodavno učenje ali kogaku tako ni bilo prva zavrnitev uradne doktrine, kakor tudi domovinsko učenje ali kokugaku ni bilo preprosto le nov prelom s svojima filozofskima predhodnikoma.

Tudi Maruyama Masao, ki je v svojih zgodnjih spisih dejansko predlagal take vrste razvojno shemo, je pozneje priznal, da je ta shema, po kateri naj bi v zgodnjem tokugavskem obdobju neokonfucianizem dosegel splošno veljavo v družbi, da pa se je univerzalnost njegovega sprejemanja začela rušiti v poznem 17. in zgodnjem 18. stoletju, ko je neokonfucianizem postal tarča kritik vse vplivnejše šole starodavnega učenja, preveč mehanicistični odsev historičnega evolucionizma in da v resnici ni skladna z dejstvi (Maruyama, 1974, xxxiv). 
Res je sicer, kakor pravi Maruyama (1974, xxxiv), da so posamezni fevdalni vladarji in tokugavska oblast v naporih doseganja stabilizacije turbulentne družbene situacije v Japonski, ki je izšla iz fevdalnih vojn, prepoznali uporabnost neokonfucijanstva $\mathrm{z}$ njegovim poudarkom na civilni in ne vojaški upravi, vendar pa so se konfucijanski klasiki in pomembni komentarji, s pomočjo katerih so konfucijanske vrednote lahko dejansko prodrle med ljudi, začeli tiskati in razširjati šele v poznem 17. stoletju:

Leta 1655 je Yamazaki Ansai, ki je odigral pomembno vlogo pri utrjevanju vsesplošne popularnosti Zhu Xijevega neokonfucijanstva, začel v Kyōtu predavati to, čemur je rekel čista verzija tistih doktrin. Toda besedilo Seikyō yōroku (Temeljni nauki modrecev), ki ga je napisal Yamaga Sokō in v katerem je pogumno napadel Zhu Xijevo šolo v celoti, je izšlo leta 1666, Itō Jinsai pa je svoj rokopis izvirnih razprav Rongo kogi (Starodavni pomeni Konfucijevih razprav) in Mōshi kogi (Starodavni pomeni Mencija) končal leta 1663. Skratka, širjenje neokonfucianizma kot ideologije in odzivi nanj v obliki šole starodavnega učenja so se razvili tako rekoč sočasno (Maruyama, 1974, xxxiv-xxxv).

\section{Od neokonfucijanstva k starodavnemu učenju kogaku 古学 in domovinskemu učenju kokugaku 国学}

Pot, temeljni pojem konfucijanske misli, je bila v Zhu Xijevi šoli utemeljena na načelu neba, zemlje in narave. To načelo preveva nebo in ljudi, zaobjema družbo in naravo, je normativni standard in naravni zakon (Maruyama, 1974, 148). Kakor piše Maruyama (1974, 148-149), so se v delih mislecev, kot so bili Yamaga Sokō, Itō Jinsai in Kaibara Ekken, različni elementi te absolutne, vseobsegajoče Zhu Xijeve poti postopoma osamosvajali: pot človeka se je ločila od poti neba, normativni standardi od človeške narave. Vendar je za te mislece pot kljub vsemu ostala transcendentalno načelo, ki ni odvisno od človeške eksistence.

Ogyū Sorai, najpomembnejši predstavnik tako imenovanega starodavnega učenja, ki je bil kritičen do Zhu Xijevega konfucijanstva, pa je zanikal, da bi bila pot ultimativno načelo, saj jo je razumel kot proizvod ljudi; ne katerihkoli ljudi, temveč kot produkt starodavnih modrecev. Ker so se ti modreci dvignili do nadzemeljske ravni, je pot ohranila absolutno in univerzalno veljavnost, toda prelom je bil storjen njena veljavnost ni več izhajala iz tega, da ustreza »resničnim « načelom narave, niti iz dejstva, da je sama po sebi ultimativna ideja, temveč le iz dejstva, da so jo vzpostavili modreci: »Kar pot naredi za pot, ni načelo, temveč avtoriteta« (Maruyama, 1974, 149).

Sorai je pot modrecev razumel kot način vladanja kraljestvu in upravljanja države in ne kot inherentno lastnost človeške narave, do katere bi se lahko dokopali s pomočjo 
introspektivne refleksije ali, kakor so temu rekli neokonfucijanci, "z vztrajanjem v spoštljivosti in z raziskovanjem načela« (kyokei kyūri 居敬窮理) (Watanabe, 2012, 163):

Tisto, čemur rečemo pot, ni ne načelo stvari ne naravna pot neba in zemlje; je pot, ki so jo vzpostavili modreci z namenom vladanja kraljestvu (Watanabe, 2012, 163).

$\mathrm{V}$ tem intelektualnem prelomu lahko prepoznamo ideološki premik kot posledico počasnega razpadanja tradicionalnih struktur "predmoderne družbe« in postopno tranzicijo $\mathrm{v}$ »modernost «, ki jo med drugim zaznamuje ideološki prelom med zasebno in javno sfero družbenega življenja. V predmodernih družbah so odnosi politične moči in zasebni ekonomski odnosi tesno povezani in ne tvorijo avtonomnih sfer, oblikovanje navidezno ločenih področij javnega in zasebnega pa je pomenilo vzpostavitev avtonomne politične sfere, s čimer se je zasebna sfera osvobodila političnih zahtev, kar je bil prvi korak na poti k oblikovanju tako imenovanega modernega individua.

Številni dejavniki so prispevali k oblikovanju šole domovinskega učenja oziroma kokugaku, vendar je bil po Maruyamovem mnenju eden ključnih dejavnikov prav Soraijeva filozofija. Četudi so pozneje nekateri zagovorniki domovinskega učenja to povezavo priznali, so v času, ko je vse bolj popularna šola kokugaku svojo identiteto gradila prav na nasprotovanju konfucianizmu, njeni člani zavzeli stališče popolnega zanikanja vsakršnega vpliva (Maruyama, 1974, 144). ${ }^{6}$

Toda ideološki prelom, ki ga je Ogyū Sorai opravil s tem, da je transcendentalno resnico nadomestil $\mathrm{z}$ avtoriteto, četudi je bila to še absolutna avtoriteta modrecev kraljev, je pomenil, da je bil duh spuščen iz steklenice. S tem je bil namreč vzpostavljen ideološki temelj, na katerem so lahko pripadniki šole kokugaku in še posebej Motoori Norinaga (1730-1801) utemeljili svojo kritiko konfucijanstva na splošno. Norinaga je modrece označil preprosto kot ljudi, ki so si pridobili podporo ljudstva s svojo avtoriteto in z globino svoje modrosti, ki so zavzeli dežele drugih in poskušali preprečiti drugim, da bi zavzeli njihove (Maruyama, 1974, 150).

Norinaga je kakor Sorai modrece razumel kot politično kategorijo, vendar jih je v nasprotju s Soraijem iz figur nadzemeljske veljavnosti ponižal na raven političnih

6 Maruyama je opozoril, da so pripadniki šole kokugaku za svojo filozofsko smer uporabljali tudi ime »šola starodavnega učenja «, zato so bili konfucijanci tistega časa prepričani, da je imela izvor v konfucijanski šoli starodavnega učenja, zaradi česar so bili pripadniki šole kokugaku še toliko bolj občutljivi glede tega vprašanja. V eseju z naslovom Aru hito no ieru koto (Kakor pravijo nekateri ljudje) je Motoori Norinaga na primer zapisal: »Nekateri pravijo, da so zapisi konfucijancev, ki proučujejo starodavne besede in izraze, odgovorni za rojstvo starodavnega učenja, vendar to ne drži. Našo šolo starodavnega učenja je ustanovil Keichū. Kar pa se tiče konfucijanske šole starodavnega učenja, je Itō deloval skoraj sočasno kakor Keichū, vendar je bil slednji nekoliko zgodnejši. Ogyū pa je bil aktiven še pozneje. Kako naj bi se potemtakem starodavno učenje zgledovalo po njih? « (Maruyama, 1974, 145). 
uzurpatorjev in je pot razumel kot produkt specifičnega zgodovinskega časa, prostora in okoliščin, v katerih se je porodila v starodavni Kitajski:

Kakor Sorai je tudi [Norinaga] razumel, da je bistvo poti njen politični namen, toda v vsebinskem smislu je Soraijevo teorijo obrnil na glavo. Za Soraija je bilo dejstvo, da je pot iznajdba (sakui) modrecev, tisto, kar ji je dajalo absolutno veljavo, medtem ko je bilo za Norinaga isto dejstvo razlog za njeno zavrnitev. Seveda so pripadniki šole domovinskega učenja začeli dvomiti o vrednosti konfucianizma, še preden so bili izpostavljeni Soraijevi šoli. Vse odkar je Keichū začel s proučevanjem japonskih klasikov, so se čedalje bolj zavedali dihotomije med konfucijansko moralo in starodavnim japonskim duhom. Vendar pa je Soraijeva šola nedvomno vplivala na smer, ki jo je ubrala njihova kritika konfucianizma. To je tista negativna vez med Soraijevo šolo in domovinskim učenjem (Maruyama, 1974, 150).

Norinaga je novo, resnično pot, ki ni bila konfucijanska pot, odkril v domorodnih animističnih verovanjih, imenovanih shintō ali "pot bogov«. Od začetka tokugavskega obdobja se je percepcija šintoizma v veliki meri naslanjala na Zhu Xijevo neokonfucijanstvo. Ko je ta konfucijanska filozofska smer postala izhodišče za interpretacijo šintoizma, je shintō, kakor piše Maruyama (1974, 154), pridobil bolj ali manj panteistično ali, bolje, panpsihično strukturo, razlagajoč nastanek univerzuma s koncepti, kot so $l i$, yin in yang, ter s petimi elementi.

Toda Norinaga je bil drugačnega mnenja. S stališča zavrnitve konfucianizma kot državne doktrine je moral zavreči vse njegove vidike, da bi lahko domorodno filozofijo »osvobodil« »škodljivega« kitajskega vpliva. Zato je zavrnil vsakršno racionalno razlago ali etično ovrednotenje šintoističnih božanstev, pri čemer je moral spremeniti razumevanje temelja starodavne poti v celoti: zanj nova pot ni bila niti naravna pot neba in zemlje niti pot, ki so jo vzpostavili ljudje, temveč pot, ki so jo začeli božanski predniki, Izanagi-no-mikoto in Izanami-no-mikoto, v skladu z željami božanstva Taka$m i-m u s u b i$, in ki jo je naprej na svoje potomce prenesla boginja sonca Amaterasu-Ōmi-kami. Zato se ta pot imenuje shintō 神道 oziroma pot božanstev (Maruyama, 1974, 156).

Motoori Norinaga, ki ni le v celoti zavrnil konfucianizma, temveč je zavrnil tudi Soraijevo kritično šolo starodavnega učenja, je torej kljub temu ostal globoko v konfucijanskem ideološkem univerzumu, in četudi je verjel, da je konfucianizem v celoti zavrnil, je ohranil njegov osrednji koncept poti. Rečeno drugače, šola kokugaku dejansko ni zavrnila ali zavrgla konfucianizma, temveč ga je le reinterpretirala v skladu z novimi družbenimi razmerami, ki so v končni fazi, po padcu tokugavskega režima, družbo preoblikovale $\mathrm{v}$ nacionalno strukturiran kolektiv. 
Za Norinaga je starodavna pot pomenila »veličastne in častitljive navade naše vzvišene dežele«, preden so bile omadeževane $\mathrm{z}$ uvozom naukov $\mathrm{z}$ azijskega kontinenta (Watanabe, 2012, 238):

»Razprostirajoč se čez Nebo in Zemljo je resnična pot enaka v vseh deželah sveta, vendar je bila pravilno razumljena le v naši Cesarski deželi. V drugih deželah se je njen prenos izgubil že v starodavnih časih « (Watanabe, 2012, 239).

$\mathrm{Z}$ razumevanjem poti kot iznajdbe modrecev in $\mathrm{z}$ njenim premikom $\mathrm{v}$ politično sfero je Sorai Norinagu omogočil, da jo je zavrnil prav na tej osnovi. Norinaga je pot, ki so jo vzpostavili starodavni modreci na Kitajskem, definiral le kot sredstvo, s katerim so uzurpatorji legitimirali svoje zločine, in kot način za prisvojitev dežele nekoga drugega in preprečitev, da bi jo kdo drug prevzel njim (Watanabe, 2012, 245). Z Norinagovimi besedami: »Volja Neba je izmišljen koncept, ki so si ga izmislili starodavni modreci na Kitajskem, da bi upravičili svoj zločin strmoglavljenja svojega gospodarja in kraje njegove zemlje« (prav tam).

\section{Konfucijanstvo in zahodno učenje rangaku 蘭学}

Usoda konfucijanstva v tokugavski družbi torej ni bila le preprosta zgodba njegove splošne vpeljave, kritike in končno popolnega razpada, temveč, kakor smo poskušali pokazati na primerih Kaibara Ekkena, Ogyūja Soraija in Motoorija Norinaga, je bila ta idejna sprememba neprekinjena reinterpretacija konfucijanstva $\mathrm{v}$ skladu s spreminjajočimi se družbenimi razmerami, ki je nazadnje omogočila njegovo implementacijo v popolnoma novi družbeni realnosti - v japonski nacionalni državi.

Kljub kritiki Zhu Xija je Kaibara Ekken verjel, da ostaja trdno v konfucijanskem intelektualnem univerzumu, ko je poskušal redefinirati spiritualizem shintōja v okviru univerzalnega načela kot identičnega s samim bistvom narave (Najita, 1975, 943). V nasprotju z neokonfucijanstvom je bil njegov epistemološki zaključek, da duhu in stvari, esenci in funkciji, vlada isto življenjsko načelo, zato ga ne bi smeli ločiti na različne kategorije realnosti (prav tam). Na osnovi pojma združujočega življenjskega načela je verjel, da je treba proučevanje stvari (butsuri no gaku 物理の学) ločiti od drugih oblik vednosti, kot sta na primer praktična etika in razvoj političnih in družbenih institucij v zgodovini (prav tam):

Skratka, narava je ena sama, toda zgodovinski običaji niso povsod enaki. To je bilo v 18. stoletju na Japonskem splošno prepričanje, ki je specifični zgodovinski »ideologiji« in naravoslovni »znanosti« omogočilo, da obstajata vzporedno, ne da bi si bili vzajemno škodljivi (Najita, 1975, 943). 
Ekken tako ni mogel sprejeti Zhu Xijevega naziranja, ki je strogo ločevalo med $l i$ 理 (načelom) in qi 気 (življenjsko silo), ter je pri tem dajal prednost kategoriji qi pred li. Qi kot energija ali materialna sila je v Zhu Xijevi filozofiji nekaj spremenljivega, medtem ko je li logično in univerzalno načelo vseh stvari. Za Ekkena, na drugi strani, pa ni bilo razlike med univerzalno obliko človeške narave in njeno pridobljeno obliko. Kakor smo videli, je reinterpretacija neokonfucijanskega koncepta univerzalnega načela Ekkenu omogočila, da ga uporabi v specifično materialističnem smislu za utrditev svojega zdravorazumskega razumevanja etike (Najita, 1975, 935). Sklepal je, da vsa človeška bitja delijo skupno "življenjsko načelo« in so si v tem smislu kot otroci narave enaka, medtem ko človeška etika, na drugi strani, nikakor ni inherentna temu življenjskemu načelu, temveč le odseva zavest človeških bitij o skupni usodi, ki si jo delijo kot otroci narave (prav tam).

Z redefinicijo šintoističnega spiritualizma s pomočjo koncepta neokonfucijanskega načela je Ekken vzpostavil ločnico med naravnim načelom in kakršnokoli etično dimenzijo in tako naravo popolnoma odtrgal od vsakršne etične vsebine, kar ga je nazadnje pripeljalo do v temelju materialistične interpretacije narave (Najita, 1975, 935-936). To mu je omogočilo vzpostaviti jasno razmejitev med partikularnim historicizmom in univerzalno znanostjo, s čimer sta konfucijanska etika in zahodna znanost lahko neproblematično sobivali vse od zgodnjega tokugavskega obdobja naprej. Ekken se je tako odpravil v Nagasaki, kjer se je lotil študija »zahodnega učenja « ali rangaku in postal cenjen botanik.

Ekken je torej radikalno preoblikoval Zhu Xijevo neokonfucijanstvo in ga spojil s študijem zahodnih naravoslovnih znanosti, pri čemer se je še vedno imel za pripadnika Zhu Xijeve šole in je bil kritičen do konfucijanske šole starodavnega učenja in njenih pripadnikov, kot sta bila Itō Jinsai in Ogyū Sorai. Konfucijanstvo v Ekkenovi interpretaciji se je $\mathrm{v}$ tem smislu uspešno prilagodilo metodologiji zahodne znanosti, ki je postala pomemben del japonske percepcije »Zahoda«. Eden pomembnih mislecev na področju zahodne znanosti na Japonskem, Sugita Genpaku (1733-1817), v svojih spominih Rangaku kotohajime (蘭学事始, Začetek zahodne znanosti) piše, da je prišlo v obdobju Meiwa (1764-72), v »času velikega razkošja in blaginje«, do vsesplošnega zanimanja za uvožene nizozemske izdelke, kot so bili barometri, higrometri, leydenske steklenice, laterna magica, ure, teleskopi in različni stekleni izdelki (Watanabe, 2012, 318).

Pripadniki šole rangaku niso trdili, da je Zahod bolj napreden, se pravi, da predstavlja naslednji korak $\mathrm{v}$ napredku civilizacije, saj $\mathrm{v}$ tistem času tovrstna zgodovinska zavest ni obstajala (Watanabe, 2012, 321). "Znanost« ali »učenje« so v tistem času dojemali izključno v okviru konfucijanskega študija, zato zanje koncept "znanosti« ni obstajal zunaj okvira konfucijanstva. Evropsko »znanost«, za katero 
je bilo značilno, da je »zbirala informacije z vsega sveta, jih podrobno proučevala, preiskovala njihova temeljna načela in spretno uporabila pridobljeno znanje« (prav tam), so japonski učenjaki razumeli v okviru konfucijanstva s pomočjo koncepta kyūri (窮理 "prodreti v načelo«). ${ }^{7} \mathrm{~V}$ tem smislu so pripadniki šole rangaku, ki so konceptualno ostali v konfucijanskih okvirih, objekt svojega proučevanja le prenesli iz Kitajske na Zahod (Watanabe, 2012, 321).

Na podlagi uspešnosti zahodne znanosti in še bolj na podlagi njene tehnološke superiornosti, ki se je pokazala ob porazu Kitajske v opijskih vojnah (1839-1842), so pripadniki šole rangaku ugotavljali, da Zahodu uspeva pravilneje in učinkoviteje "prodirati v načelo« kakor deželam, ki so pod vplivom Zhu Xijevega neokonfucijanstva (Watanabe, 2012, 322).

\section{Zaključek}

Če so pripadniki šole kokugaku, kot na primer Motoori Norinaga, odkrili resnično pot $\mathrm{v}$ domorodni poti božanstev (shintō), so pripadniki šole rangaku in številni drugi uspešnost zahodnih narodov razumeli kot dokaz, da se resnična pot skriva $\mathrm{v}$ zahodnem načinu razmišljanja. Ko so opisovali dosežke zahodne civilizacije, so besedo »civilizacija« v japonščino prevedli kot bunmei. To je v osnovi konfucijanski pojem (wenming 文明), ki opisuje stanje, $\mathrm{v}$ katerem se pot pravilno izvaja in kultura cveti (Watanabe, 2012, 327).

Skratka, v temelju Zhu Xijeve misli je bilo verjetje v apriorni obstoj načela, po kitajsko $l i$, ki mu morajo slediti človeške moralne norme. Zhu Xi je predpostavil nekakšno dvojno strukturo, v kateri so človeški zakoni formulirani kot aplikacija naravnega zakona, medtem ko Soraijevi modreci, nasprotno, take transcendentne norme kot etičnega vzora ne poznajo. Zakoni, ki so jih vzpostavili, so sami na sebi pot (Watanabe, 2012, 163-164). To preoblikovanje neokonfucijanske doktrine je Motooriju Norinagu in drugim pripadnikom šole kokugaku omogočilo, da so naredili še korak naprej in v celoti zavrnili pot modrecev. Resnično naravo poti so nato pripisali »veličastnim in častitljivim običajem naše Vzvišene dežele«, preden so bili ti običaji kontaminirani $\mathrm{z}$ vdorom učenja, ki je prišlo $\mathrm{z}$ azijskega kontinenta (Watanabe, 2012, 238). Pripadniki šole rangaku, na drugi strani, pa so v napredni zahodni civilizaciji prepoznali pravo pot, ki se je na Japonskem in Kitajskem izgubila.

Konfucijanski koncept poti je potemtakem ostal osrednji koncept japonskih intelektualnih krogov, pri čemer je doživel opisane transformacije in reinterpretacije.

7 Koncept kyūri se pojavi v delu Shuogua zhuan (說卦傳 Razlaga trigramov), enem od komentarjev h konfucijanskemu klasiku Knjigi premen (Yijing 易經), dodatno pa ga je opredelil Zhu Xi (Watanabe, 2012, 321). 
Nova nacionalna država, ki se je porodila iz revolucionarnih dogodkov v zadnjih letih tokugavskega režima, je na vsebinski ravni postala prav konglomerat omenjenih ideoloških smeri. Mejdžijevska država je bila zamišljena kot moderna, industrijsko razvita in tehnološko napredna država, ki je z velikim navdušenjem prevzela tehnološke dosežke zahodne znanosti in moderne institucije liberalne buržoazne nacionalne države, hkrati pa je bila ta preobrazba interpretirana skozi ideološko prizmo ideje wakon yōsai, se pravi ideje, da je to zahodno znanje kompatibilno $\mathrm{z}$ »japonskim duhom«, kakor ga je formulirala šola kokugaku. "Zahodno znanje« v interpretaciji šole rangaku in "japonski duh « v interpretaciji šole kokugaku sta se uspešno prepletla $s$ pomočjo še vedno trdne konfucijanske idejne paradigme, saj se ne rangaku ne kokugaku, ne glede na to, kako močno sta nasprotovali konfucianizmu, nista mogli osvoboditi njegovega prevladujočega vpliva.

Nova mejdžijevska država, ki se je hkrati s tem, ko je postala moderna, industrijska in kapitalistična država, ideološko dojemala kot osvobojena kitajskega vpliva in utemeljena na domorodnem šintoističnem nacionalizmu, je dejansko ostala v temelju konfucijanska družba. Čeprav so številni konfucianizem zavračali iz ideoloških razlogov, so si drugi prizadevali reinterpretirati njegov konceptualni univerzum $\mathrm{v}$ skladu z novimi uvoženimi pojmi z Zahoda. Na primer, mejdžijevski liberalni mislec in goreč podpornik Rousseaujevih idej Nakae Chōmin (1847-1901) je trdno verjel, da je pojem rigi 理義 (razum in pravičnost), ${ }^{8}$ ki so ga opisali Mencij, Liu Zongyuan in drugi, identičen idejam, ki so jih Zahodnjaki opisovali s koncepti, kot so »svoboda«, »enakost« in »demokracija» (Watanabe, 1997, 195).

Kritika Zhu Xijeve filozofije v okviru konfucijanskih šol, nadaljnji kritični preobrat $\mathrm{v}$ obliki šole starodavnega učenja, zavrnitev konfucianizma v obliki domovinskega učenja oziroma kokugaku in priljubljenost zahodnega učenja oziroma šole rangaku niso pomenili počasnega razpadanja konfucianizma, ki naj bi ga v končni fazi v celoti odplaknila družbena in politična revolucija, ki je sledila mejdžijevskemu prevratu, temveč je šlo prej za proces počasne reinterpretacije znotraj vselej spreminjajočega se družbenega konteksta.

$\mathrm{V}$ določenem smislu torej konfucianizem, ki so ga prevzeli $\mathrm{v}$ zgodnjem tokugavskem obdobju, nikakor ni bil monoliten in ortodoksen politični sistem, ki bi ga lahko preprosto opisali z enotnim izrazom "neokonfucijanstvo«, temveč je bil

8 Nakae Chōmin je imel izjemno rad koncept rigi 理義, ki vključuje temeljni konfucijanski pojem $r i$ 理 (po kitajsko $l i$ ) oziroma "načelo«. Zato je tudi zahodni koncept »filozofije« prevedel kot rigaku 理学 (študij načela). Ko so japonski misleci v poznem 19. stoletju vpeljevali zahodne filozofske koncepte, so jih namreč prevajali prav s pomočjo konfucijanske terminologije, pri čemer je koncept $r i$ igral ključno vlogo. Tako so nastale številne besede, ki so danes v vsakdanji rabi in ki vse vključujejo koncept $r i$, kakor na primer »teorija«(riron 理論), »ideal« (risō 理想), »logika« (ronri 論理), »razum« (risei 理性), »resnica«(shinri 真理), »ideja (rinen 理念) itd. 
kompleksna mreža filozofskih tokov, ki so bili vselej v dialogu drug z drugim. Če kaj, je bil konfucianizem mejdžijevskega obdobja, se pravi konfucianizem, ki je namesto na družbenem statusu utemeljene fevdalne družbe podpiral kapitalistično nacionalno državo, bolj monoliten in ortodoksen v svoji obliki. Konfucijanska misel v vseh svojih interpretativnih različicah torej ni bila primerna le za to, da ideološko podpre fevdalno statusno družbo, in obsojena na propad skupaj s propadom te družbe, temveč se je bila zmožna prilagoditi novim razmeram, $\mathrm{v}$ katerih je nacionalizem postal prevladujoča ideološka interpretacija družbene realnosti.

\section{Literatura}

Arrighi, G. in dr., Anti-Systemic Movements, London 2012.

Carus, P., Philosophy in Japan. Monist 9/2, 1899, str. 273-281.

Goody, J., Vzhod na Zahodu, Ljubljana 2013.

Gusfield, J. R., Tradition and Modernity: Misplaced Polarities in the Study of Social Change, American Journal of Sociology, 72/4, 1967, str. 351-362.

Hobsbawm, E., Terence R. (ur.), The Invention of Tradition, Cambridge 2012.

Kanazawa, S., Miller, A. S., Order by Accident: The Origins and Consequences of Conformity in Contemporary Japan, Boulder 2000.

Lopez, D., Modern Buddhism: Readings for the Unenlightened, London 2002.

Maruyama, M., Studies in the Intellectual History of Tokugawa Japan, Princeton 1974.

Najita, T., Intellectual Change in Early Eighteenth-Century Tokugawa Confucianism, The Journal of Asian Studies 34/4, 1975, str. 931-944.

Ooms, H., Makoto, K., Introduction to »The Nature of Early Tokugawa Confucianism« by Kurozumi Makoto, Journal of Japanese Studies 20/2, 1994, str. 331-335.

Plehanov, G., V obrambo marksizma, Ljubljana 1955.

Said, E. W., Orientalizem: zahodnjaški pogled na Orient, Ljubljana 1996.

Seth, S., Nationalism, Modernity, and the »Woman Question« in India and China, The Journal of Asian Studies 72/2, 2013, str. 273-297.

Watanabe, H., Higashi Ajia No Ōken to Shisō, Tokio 1997.

Watanabe, H., A History of Japanese Political Thought, 1600-1901, Tokio 2012. 


\section{Luka Culiberg}

\section{Tradicija, modernost in vloga konfucianizma pri izgradnji japonske nacionalne države}

Ključne besede: konfucianizem, kogaku, kokugaku, rangaku, narod, tradicija, modernost

Članek sledi razvoju konfucijanske misli na Japonskem in pokaže, kako je konfucijanstvo s svojim osrednjim konceptom poti ostalo idejni temelj japonskih intelektualnih krogov, pri čemer je doživelo številne transformacije in reinterpretacije. Univerzalna pot kot naravno načelo je pri mislecih šole kogaku postala produkt modrecev, pri pripadnikih šole kokugaku pa je prišlo do obrata v japonsko šintoistično tradicijo. Pripadniki šole rangaku so v konfucijanski univerzum posvojili zahodno znanost in tehnologijo. Nova nacionalna država, ki so jo vzpostavili revolucionarji v obdobju Meiji, je na vsebinski ravni postala prav zmes omenjenih idejnih smeri. Mejdžijevska država je bila moderna, industrijska in tehnološko napredna država, ki se je v temelju identificirala s cesarskim sistemom in šintoistično tradicijo, njeno institucionalno ogrodje pa je skupaj držala trdna ideologija konfucianizma. 
Luka Culiberg

\section{Tradition, Modernity and the Role of Confucianism in the Creation of the Japanese Nation-State}

Keywords: Confucianism, kogaku, kokugaku, rangaku, ideology, nation, tradition, modernity

The paper explores the development of Confucian thought in Japan, showing that Confucianism, with its key concept of the Way, remained the foundation of Japanese intellectual circles even as it underwent numerous transformations and reinterpretations. The universal Way as a natural Principle was transformed into a product of the sages within the framework of the kogaku school, whereas the kokugaku school applied the concept of the Way to the Japanese Shinto tradition. The adherents of the rangaku school, on the other hand, adopted Western science and technology in the Confucian intellectual universe. The new nation-state built by the Meiji revolutionaries thus became a mixture of all these intellectual currents. The Meiji state was a modern, industrial and technologically advanced state that identified itself with the imperial system and native Shinto tradition while being held together institutionally by a firm Confucian ideology. 